\title{
Comprehensive and Rapid Real-Time PCR Analysis of 21 Foodborne Outbreaks
}

\author{
Hiroshi Fukushima, Kazunori Katsube, Yoshie Tsunomori, Ryoko Kishi, \\ Junko Atsuta, and Yuko Akiba
}

Shimane Prefectural Institute of Public Health and Environmental Science, 582-1 Nishihamasada, Matsue City,
Shimane 690-0122, Japan

Correspondence should be addressed to Hiroshi Fukushima, fukushima-hiroshi@pref.shimane.lg.jp

Received 4 November 2008; Revised 19 December 2008; Accepted 4 February 2009

Recommended by Todd R. Callaway

\begin{abstract}
A set of four duplex SYBR Green I PCR (SG-PCR) assay combined with DNA extraction using QIAamp DNA Stool Mini kit was evaluated for the detection of foodborne bacteria from 21 foodborne outbreaks. The causative pathogens were detected in almost all cases in 2 hours or less. The first run was for the detection of 8 main foodborne pathogens in 5 stool specimens within 2 hours and the second run was for the detection of other unusual suspect pathogens within a further 45 minutes. After 2 to 4 days, the causative agents were isolated and identified. The results proved that for comprehensive and rapid molecular diagnosis in foodborne outbreaks, Duplex SG-PCR assay is not only very useful, but is also economically viable for one-step differentiation of causative pathogens in fecal specimens obtained from symptomatic patients. This then allows for effective diagnosis and management of foodborne outbreaks.
\end{abstract}

Copyright (๑) 2009 Hiroshi Fukushima et al. This is an open access article distributed under the Creative Commons Attribution License, which permits unrestricted use, distribution, and reproduction in any medium, provided the original work is properly cited.

\section{Introduction}

The introduction of real-time PCR in foodborne outbreak investigations provides an opportunity for rapid detection of pathogens in food and clinical settings [1]. The benefits to public health administration from rapid real-time PCR assays are most notable after comprehensive and rapid detection of bacteria. The results can quickly inform a public health administrator about the causative pathogens of foodborne outbreak, allowing a more accurate, effective, and timely response. Abubakar et al. [2] implied in the Health Technology Assessment program (now part of the National Institute for Health Research, UK) that the feasibility of conversion to rapid methods such as multiplex PCR and DNA microarrays is dependent on localized considerations, including the community prevalence rates for specific pathogens, the skill base, and subsequent training costs for laboratory staff and spare capacity available to ensure adequate laboratory space for new equipment. Although these tests look promising, further studies are necessary to assess their usefulness [2].
Apart from saving time, real-time PCR is sensitive, highly specific and offers the potential for quantification [3]. The risk of cross-contamination is significantly reduced, and high-throughput performance and automation are possible since no post-PCR manipulations are required [4]. In principle, two different chemistries are available for realtime detection of PCR products: fluorescent probes that bind specifically to certain DNA sequences and fluorescent dyes that intercalate into any double-stranded DNA. Fluorescentprobe based real-time PCR (TaqMan PCR) studies to detect causative pathogens from foodborne outbreaks in feces using TaqMan probes have been carried out [3-6]. TaqMan PCR assays require the availability of primers and probes that must be selected according to very rigid criteria. Use of simple, cheaper double-stranded DNA-binding dye SYBR green I for detection of PCR amplicons (SG-PCR) overcomes this limitation. Therefore, real-time PCR could be applied without the need for fluorescent probes [7]. In the absence of probes, the specificity of the reaction is determined on the basis of the melting temperature $\left(T_{m}\right)$. The advantages of SGPCR over TaqMan PCR include the relative simplicity and 
reduced cost of SYBR Green I compared to TaqMan probes [8]. Recently, the application of SG-PCR for the detection of foodborne bacteria in different samples has been increased [1, 9-12]. Duplex SG-PCR assays have been carried out to detect causative bacteria in feces from foodborne outbreaks $[4,10,13]$.

We previously reported a set of four duplex SG-PCR assays for one-step differentiation of 8 genes of foodborne pathogens in DNA extracted from 5 feces using 32 capillary tubes of LightCycler (Roche). The first run was for the detection of 8 main foodborne pathogens and the second run was for the other pathogens. We reported here that improved diagnostic duplex SG-PCR assays were upgraded with new highly sensitive primer pairs for 11 foodborne pathogens. These assays successfully identified the causative pathogens of foodborne outbreaks caused by enteropathogenic Escherichia coli, enterohemorrhagic E. coli, astA-positive E. coli, Plesiomonas shigelloides, Vibrio parahaemolyticus, Campylobacter jejuni, Clostridium perfringens, Bacillus cereus, or Staphylococcus aureus in 21 cases from 2002 to 2007. This assay is simple, rapid, inexpensive, reliable as well as suitable for comprehensive, rapid detection of causative pathogens in foodborne outbreaks.

\section{Material and Methods}

2.1. Bacterial Strains. The 27 foodborne bacteria used in this study are E. coli (enteroinvasive E. coli (EIEC), enteropathogenic E. coli (EPEC), enterohemorrhagic E. coli (EHEC), enterotoxigenic E. coli (ETEC), and enteroaggregative E. coli (EAEC)), Shigellasonnei, Salmonella Enteritidis, Yersinia enterocolitica, Yersinia pseudotuberculosis, Providencia alcalifaciens, Plesiomonas shigelloides, Campylobacter jejuni, C. coli, Vibrio cholerae, TDH-positive V. parahaemolyticus, TRH-positive V. parahaemolyticus, Aeromonas hydrophila, Staphylococcus aureus, emetic Bacillus cereus, enterotoxigenic $B$. cereus, and Clostridium perfringens (Table 1). Bacterial cultures and viable-cell counting were described in a previous report [10]. For template DNA of each foodborne pathogen as a PCR control, $200 \mu \mathrm{L}$ of each bacterial culture $\left(10^{8} \mathrm{CFU} / \mathrm{mL}\right)$ was treated with a QIAamp DNA Stool Mini kit (Qiagen) in the same procedure as the following stool treatments.

2.2. Primer Design. The 22 primer pairs used in this study for the detection of E. coli (EIEC, EPEC, EHEC, ETEC, and EAEC), Salmonellaenterica, Shigella spp., Y. enterocolitica, Y. pseudotuberculosis, P. alcalifaciens, C. jejuni, C. coli, V. cholerae, V. parahaemolyticus, A. hydrophila, P. shigelloides, $S$. aureus, $C$. perfringens, and $B$. cereuswere described in our previous reports $[10,13]$ for cases 1 to 19 . The newly designed 22 primer pairs listed in Table 2 were used for cases 19 to 21 . In this study, 10 primer pairs (marked with * in Table 2) were newly designed or selected from earlier publications (see Table 2 references). The 4 primer pairs (ces, yadA-X, CCceuE, and aggR-Z) were newly designed. The ces primer was constructed from cereulide synthetase gene of emetic $B$. cereus [4], the yadA-X primer from yadA gene on the plasmid present in virulent Yersinia spp. [24], the CCceuE primer from ceuE gene encoding of a lipoprotein component of a binding-protein-dependent transport system for the siderophore enterochelin of $C$. coli [25], and the aggR-Z primer from $a g g R$ gene encoding of a transcriptional activator for EAEC aggregative adherence fimbria I expression [26]. To determine the specific primers ces, yadA-X, CCceuE, and aggR-Z, the genes of ces, yadA, ceuE, and $\operatorname{aggR}$ that were expected to be unique were selected with the Basic Local Alignment Search Tool (BLAST) program within GenBank and were designed by Biosearch Technologies Inc. (USA). Other primer pairs were those used in earlier publications (see Table 2 references). All oligonucleotide primers were synthesized by Invitrogen (Yokohama, Japan) or Biosearch Technologies Inc. (USA).

2.3. Duplex SG-PCR with Feces. Feces $(1 \mathrm{~g})$ from 5 patients were weighed aseptically from the mass sample collected for virological inspection, placed into sterile tubes, and homogenized with $9 \mathrm{~mL}$ of distilled water. Then, $200 \mu \mathrm{L}$ of stool suspension was treated with a QIAamp DNA Stool Mini kit. For real-time PCR, we used SYBR Premix EX Taq (Takara, Japan), 32 glass capillary tubes, and a LightCycler instrument (Roche Diagnostics, Mannheim, Germany) as described by the manufacturer. Duplex SG-PCR was performed using 32 glass capillary tubes with 4 groups of 2 primer sets on the LC instrument for each run. Analysis of each group of primer pairs was made in 8 glass capillary tubes; each of which included 1 negative DNA control consisting of PCRgrade water, 2 positive controls, and template DNA from 5 feces. The first run of duplex SG-PCR was analyzed using 4 primer sets selected from 11 primer sets described in our previous reports $[10,13]$. The newly first run primer set including eae plus FemB, AB plus EAST1, Tdh plus Ces-TM, and Styinva plus GAP (see Table 2) was used for analysis of cases 19 to 21 . The second run was analyzed using 4 primer sets selected from the following primer sets: LT plus AHH1, STa plus PSG, aggR-Z plus virA, SG plus PAG and the third run using yadA-X plus CCceuE, and hlyA plus Trh. The eaeA-positive samples were analyzed by simple PCR using primers JMS1 and JMS2. Each reaction tube contained $10 \mu \mathrm{L}$ of SYBR Premix EX Taq, $6.8 \mu \mathrm{L}$ of PCR-grade $\mathrm{H}_{2} \mathrm{O}, 0.4 \mu \mathrm{L}$ of both forward and reverse primers $(10 \mu \mathrm{M})$ for the target gene of two foodborne pathogens, and $2 \mu \mathrm{L}$ of template DNA in a $20 \mu \mathrm{L}$ PCR mixture. The assay cycling profile was $95^{\circ} \mathrm{C}$ for 10 minutes, followed by 30 cycles of denaturation at $95^{\circ} \mathrm{C}$ for 5 seconds and then annealing at $60^{\circ} \mathrm{C}$ for 20 seconds. Fluorescence signals were measured once per cycle at the end of the extension step. After PCR amplification, a melting temperature curve analysis was done. Next, the LightCycler PCR products were cooled to $65^{\circ} \mathrm{C}$ and then heated to $95^{\circ} \mathrm{C}$ at a rate of $0.1^{\circ} \mathrm{C}$ per second. The fluorescence signals obtained were continuously monitored to confirm amplification specificity during 1 hour of analysis. The products' melting temperature peaks were calculated by performing 10 or more assays per sample and were based on the initial fluorescence curve found by plotting the negative derivative of fluorescence over temperature 


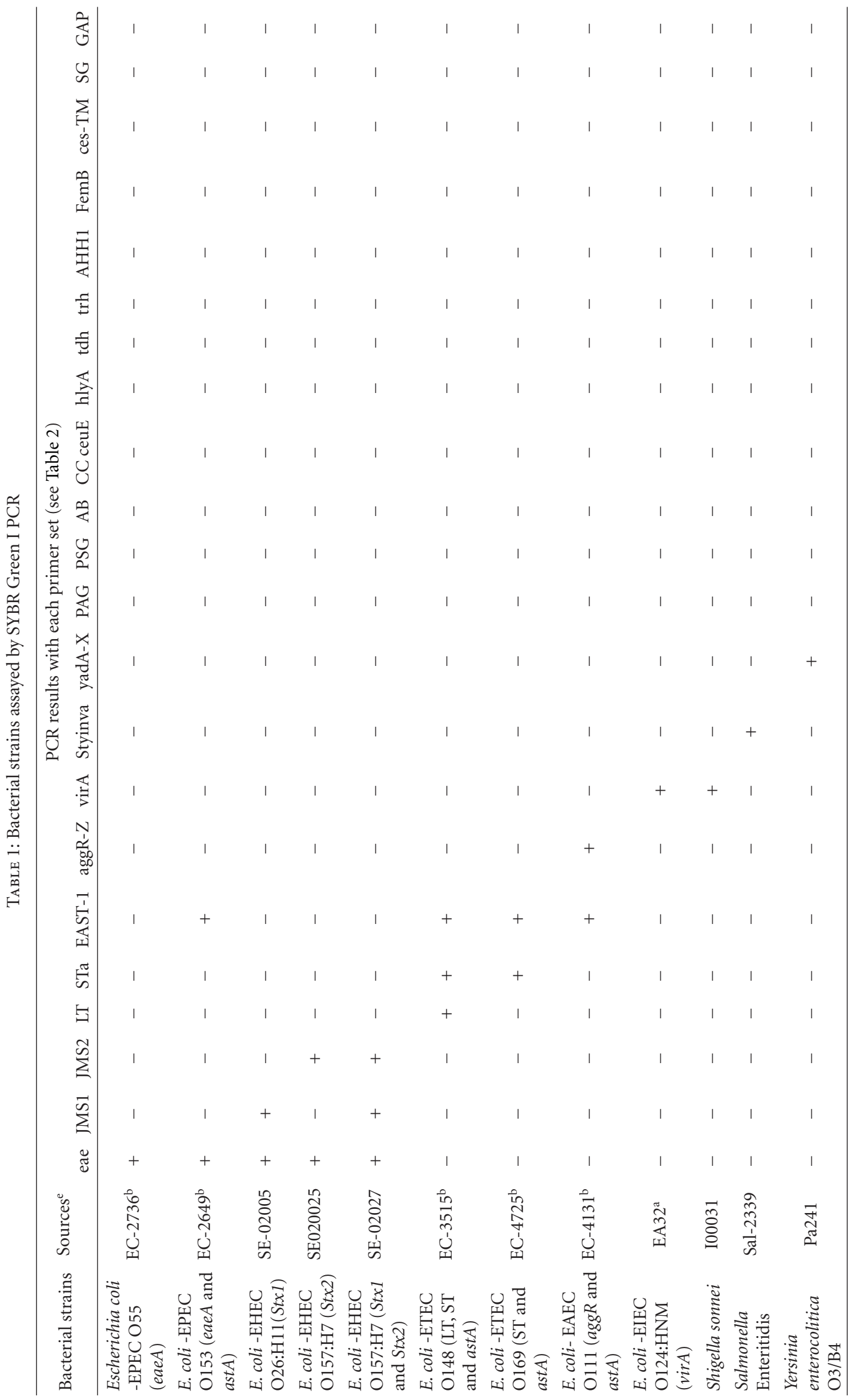




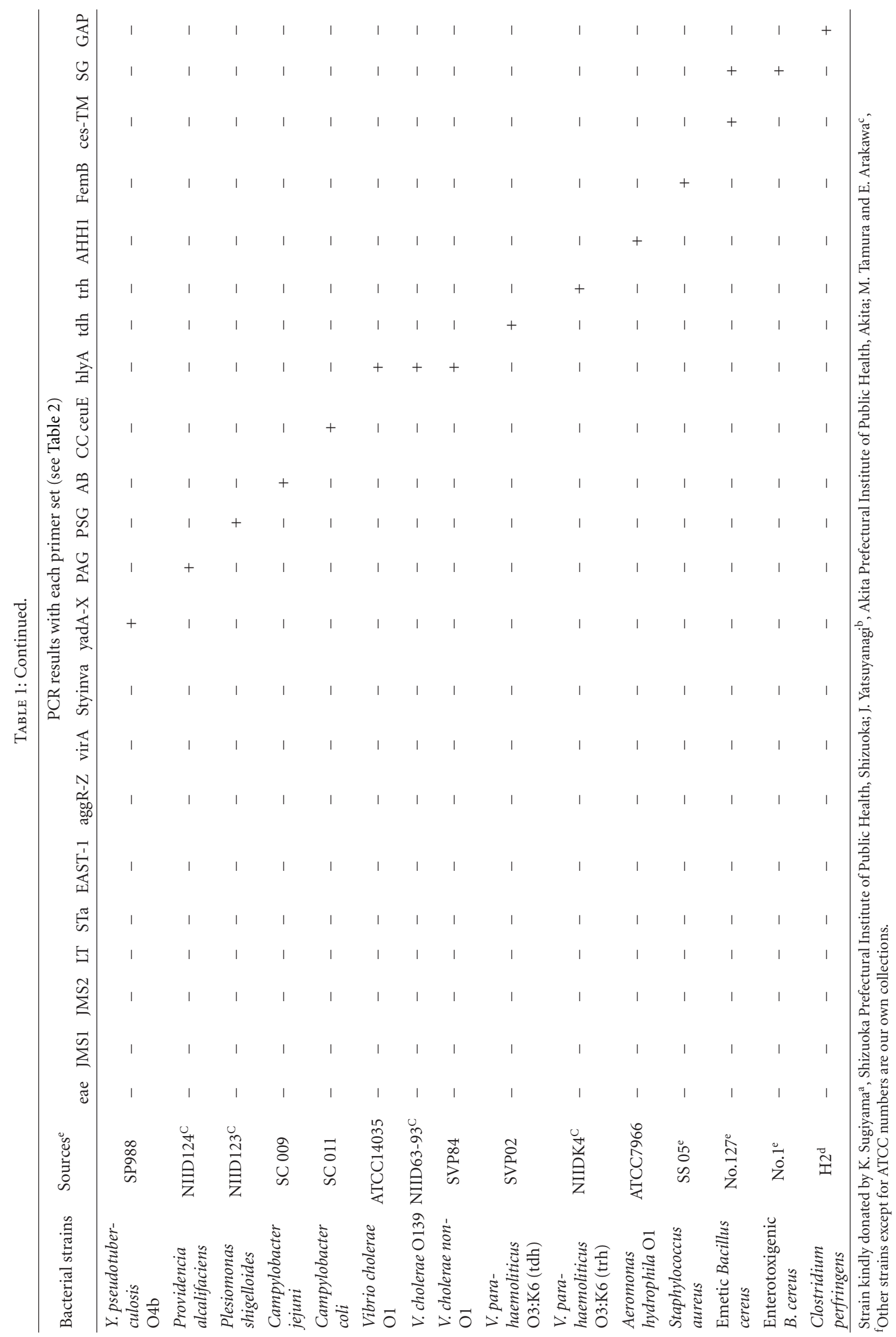




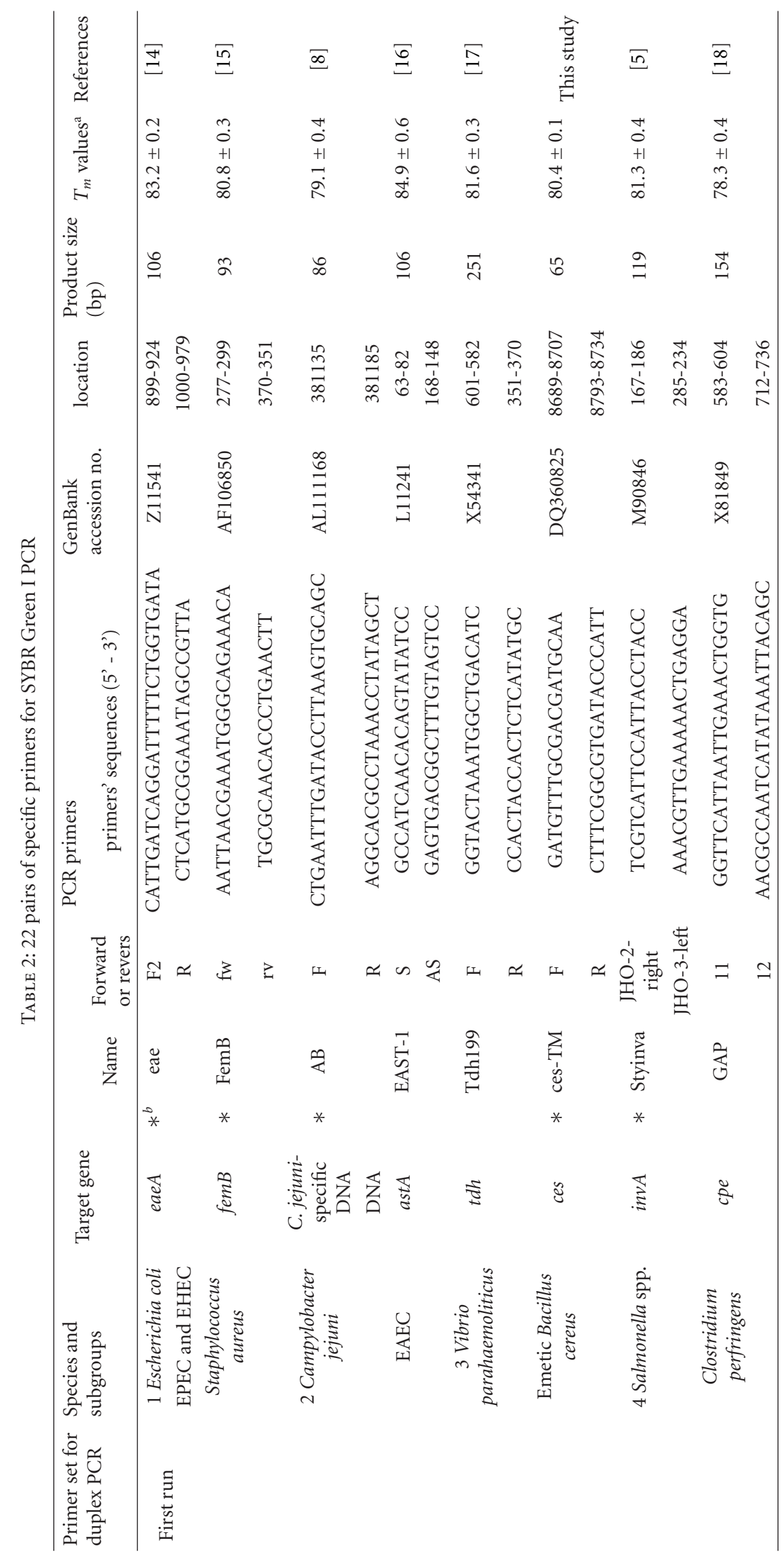




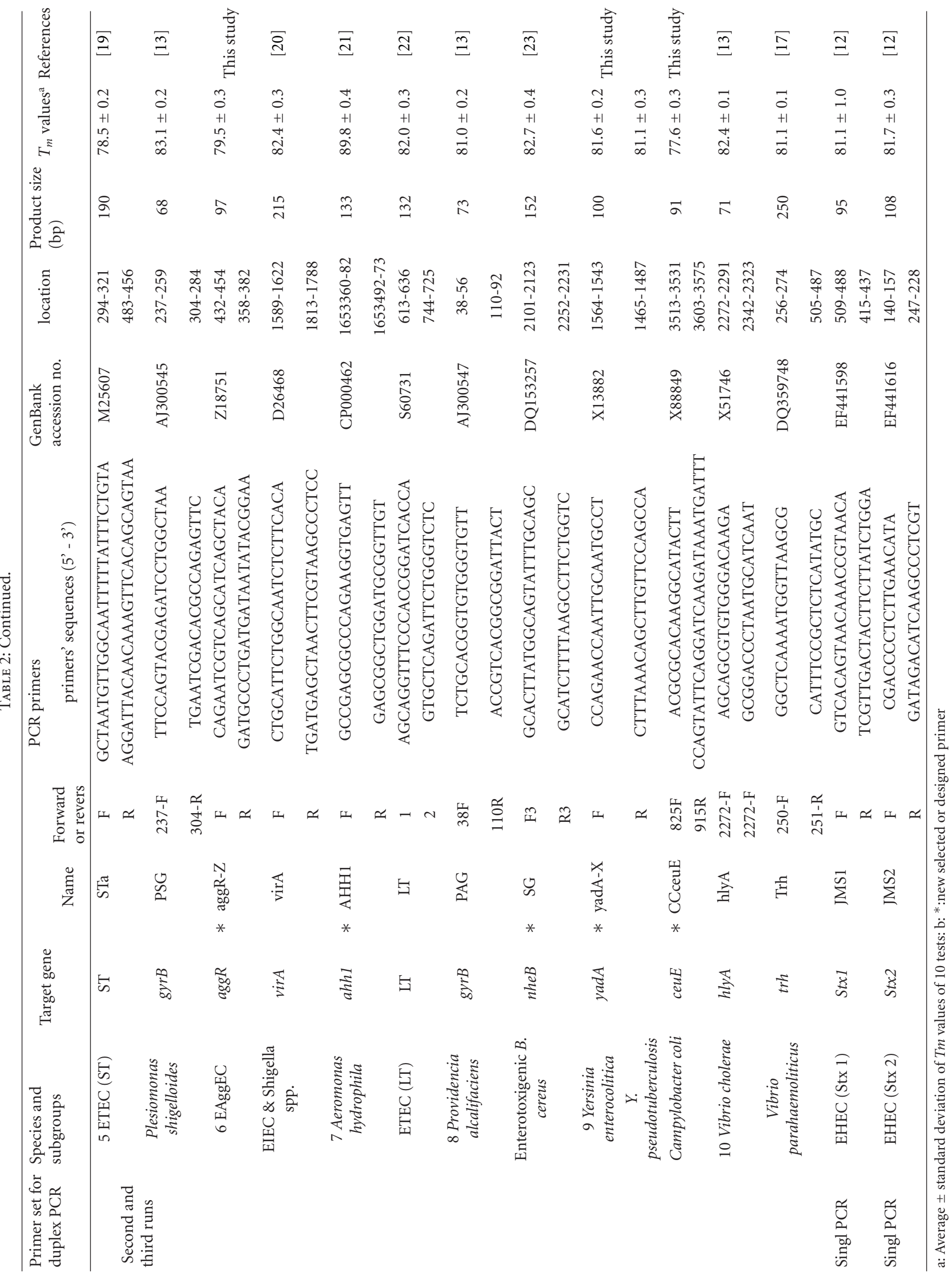


versus temperature. To quantify target bacteria in feces, DNA samples extracted with the QIAamp DNA Stool Mini kit from target bacteria were used to form a standard curve. Two microliters of a serial 10-fold dilution of DNA (Easy Dilution from Takara, Japan) were prepared and analyzed under the conditions specified above.

2.4. Duplex SG-PCR Analysis in 21 Foodborne Outbreaks. 21 foodborne outbreak cases examined by duplex SG-PCR in Shimane Prefecture, Japan from 2002 to 2007 are shown in Table 3.

\section{Results and Discussion}

3.1. Duplex SG-PCR Procedures. We previously reported duplex SG-PCR assays for detection of 19 species of foodborne pathogens using 22 primer pairs [10, 13]. After that, more accurate duplex SG-PCR assays were designed by 10 more sensitive and specific primers including 6 primers (FemB, AB, ces-TM, Styinva, SG, and AHH1) selected from earlier publications (see references in Table 2) and 5 new primers (eae, aggR-Z, yadA-X, and CCceuE) constructed in this study. The new primer set was used for cases 19 to 21. Real-time SG-PCR procedures using 22 primer pairs for the detection of 15 bacterial species, including $5 \mathrm{E}$ coli subgroups, were developed for the duplex assay. The primer sequence, target, SG-PCR product size, $T_{m}$ values (mean plus standard deviation from a range of 10 assays), specificities, and references are summarized and listed in Tables 1 and 2. The primer virA detects virA gene of Shigella spp. and EIEC; the primer eae detects eaeA gene of EPEC and EHEC, and the primer EAST-1 detects astA gene of EAEC and ETEC. Primer hlyA detected hlyA gene of $V$. cholerae strains $\mathrm{O} 1$ and $\mathrm{O} 139$ as well as non-O1 strains. The primer SG for the detection of nheB (nonhemolytic enterotoxin B) gene of $B$. cereus cross-reacts with enterotoxigenic and emetic strains and the primer ces-TM detects cereulide synthetase gene of emetic strain of $B$. cereus. The nheB and ces gene positive strains were identified with emetic strains and the nheB gene positive and ces gene negative strains with enterotoxigenic strains. A new primer yadA-X for Yersinia adhesion reacts with virulent $Y$. enterocolitica and $Y$. pseudotuberculosis, but not with nonpathogenic strains of Yersinia spp. (data not shown). Other primers, including new primers aggR-Z and CCceuE, specifically detect each gene of EAEC and C. coli. Food-borne Outbreak Investigation Report (http://www.mhlw.go.jp/topics/syokuchu/), Ministry of Health, Labor and Welfare, Japan during 2005 to 2007 shows that $97 \%$ of foodborne outbreaks were caused by the following 7 species of foodborne pathogens: S. enterica (58.3\%), C. jejuni (15.2\%), TDH-producing $V$. parahaemolyticus $(8.3 \%)$, S. aureus $(7.2 \%)$, C. perfringens (3.6\%), emetic B. cereus (1.6\%), EHEC (2.9\%), and other virulent E. coli $(2.1 \%)$ which include astA-positive E. coli which is a strain of $E$. coli that does not possess any diarrheagenic characteristics except the EAEC heat-stable toxin 1 (EAST1) gene and is frequently isolated in diarrhea outbreaks [27]. Using of 4 primer sets of 2 primer pairs, including newly selected or designed 6 primer pairs, for the detection of 7 main foodborne pathogens and astA-positive E. coli in the first run of duplex SG-PCR brought out the comprehensive, rapid, and sensitive detection of causative pathogens in foodborne pathogens to cases 19 to 21 (Table 2 and Figures 1 and 2). The second run of duplex SG-PCR used 4 primer sets and the final run utilized 2 primer sets selected from the remaining 4 primer pairs. The primers JMS1 and JMS2 were used for the single PCR detection of stx 1 and/or stx 2 genes from the eaeA gene-positive samples for the confirmation of EHEC. Figures 1 and 2 show the $T_{m}$ curves of the duplex SG-PCR products of the template DNA samples in each run. In duplex SG-PCR assay with two primer pairs, each PCR product was generated with a different $T_{m}$ curve. These could be resolved in a LightCycler by using $T_{m}$ curve analysis when a target bacterium was present in the reaction tube.

\subsection{Using Duplex SG-PCR for Identification of the Causative} Agent in 21 Foodborne Outbreaks. Table 3 shows epidemiological and clinical investigations in 21 foodborne outbreaks examined by duplex SG-PCR analysis in Shimane Prefecture, Japan from 2002 to 2007. From samples of feces, we used a combination of duplex SG-PCR assay with DNA extraction using a QIAamp DNA Stool Mini kit. The SG-PCR assay is rapid, specific, and sensitive as a detection technique. The DNA extraction of 5 stool specimens with the QIAamp DNA Stool Mini kit was carried out within 1 hour and it effectively removed inhibitors present in feces. The duplex SG-PCR assay was also carried out within 1 hour. The 7 species (listed previously) of foodborne bacteria, which included 3 groups of E. coli, were detected from 111 (58.1\%) of 191 feces in 21 cases by duplex SG-PCR. Then these causative agents were isolated and identified after 2 to 4 days. With the exception of two cases (cases 10 and 11), the first run of duplex SG-PCR confirmed the presence of a pathogen in $54(58.1 \%)$ of 93 feces in $19(90.5 \%)$ cases within 2 hours. The exceptions were case 10 where a confirmation test was necessary to detect the eaeA gene of EHEC $\mathrm{O} 26$ and case 11 where astA-positive E. coli was detected on the third run. In the first run, DNA samples extracted from 5 feces $(1,3,4$, or 7 feces in 6 cases) of symptomatic patients were used and the causative pathogens were detected from 1 to 5 samples: 1 (in 8 cases: 1, 2, 4, 7, $8,15,19$, and 21), 2 (in 3 cases: 9, 13, and 20), 3 (in 3 cases: 16, 18, and 21), 4 (in 3 cases: 5,6 , and 17), and 5 samples (in 3 cases: 3,12 , and 14). Then the causative pathogens were later isolated in a routine laboratory. In cases 11 and 12, C. perfringens or $C$. jejuni was detected by duplex SG-qPCR with more than $10^{5} \mathrm{CFU} / \mathrm{g}$ feces from only 1 sample and $C$. perfringens was then also isolated from only 1 of 46 samples and $C$. jejuni from only 1 of 16 samples by culture method. Therefore, the infections with both these pathogens were determined to be sporadic cases and they were immediately eliminated as causative pathogens in cases 11 and 12. It was confirmed that duplex SG-PCR analysis of 5 feces collected from symptomatic patients was ultimately the most effective screening method for foodborne pathogens in foodborne outbreaks $[10,13]$. 


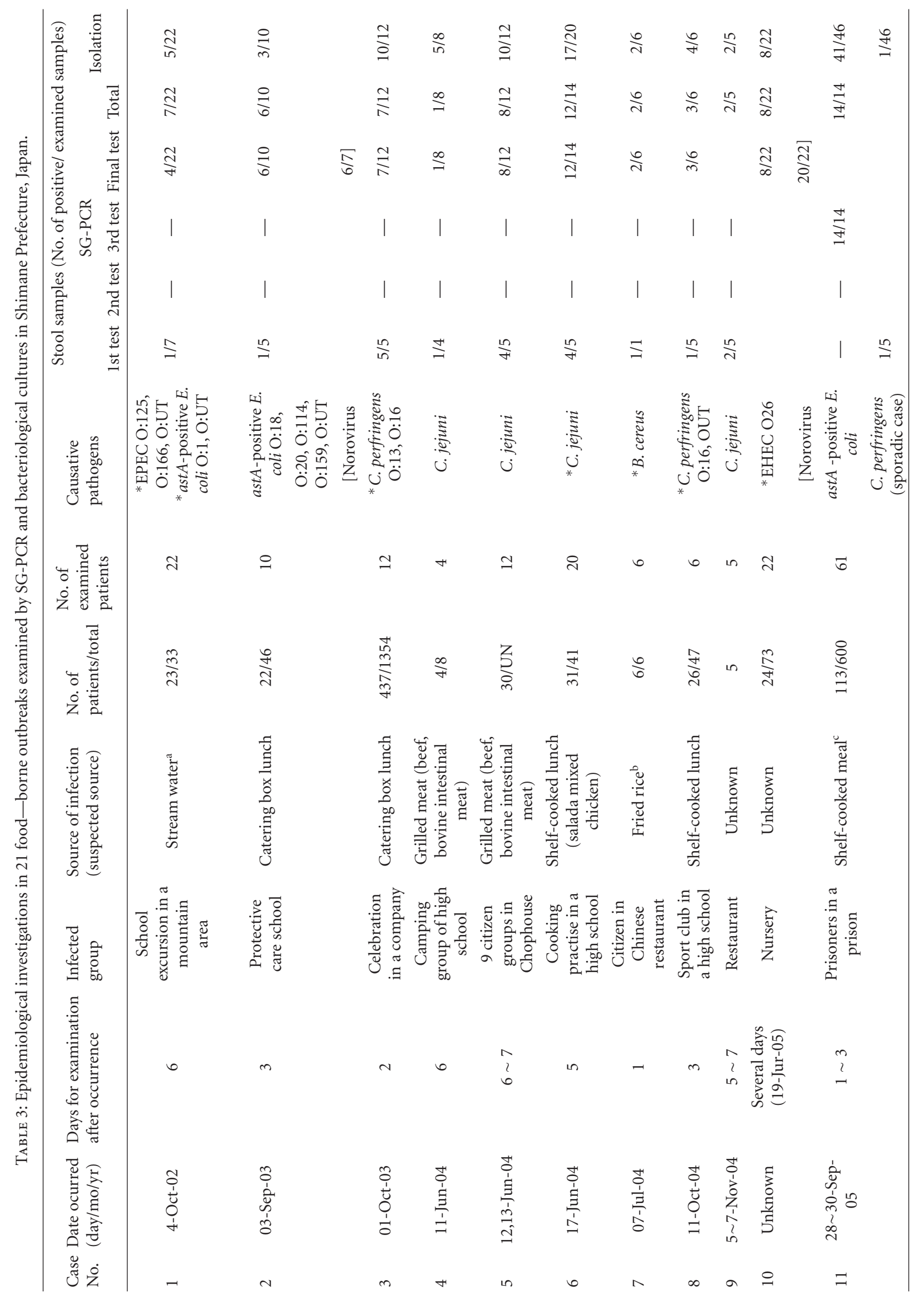




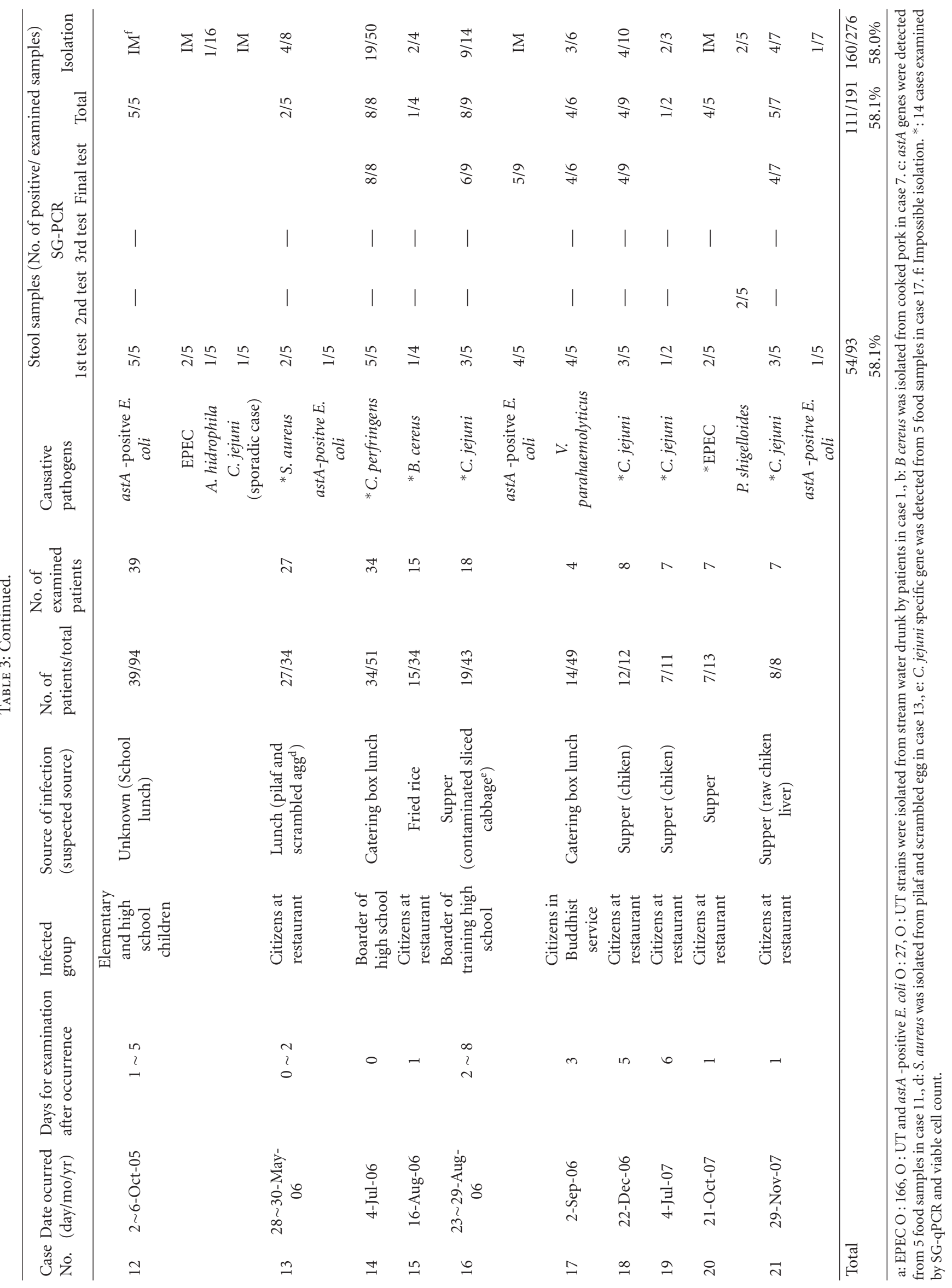




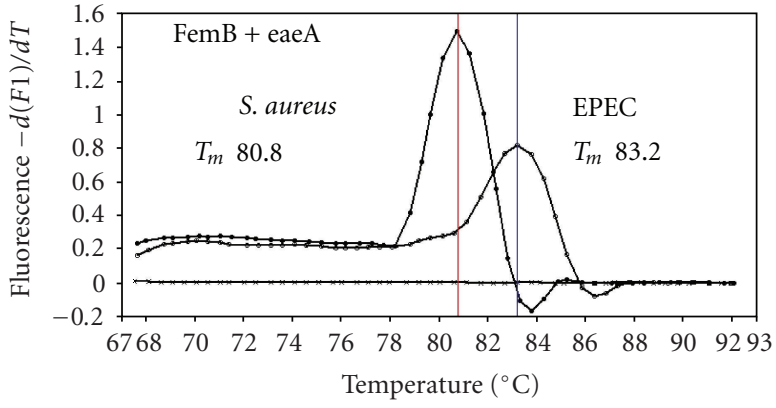

(a)

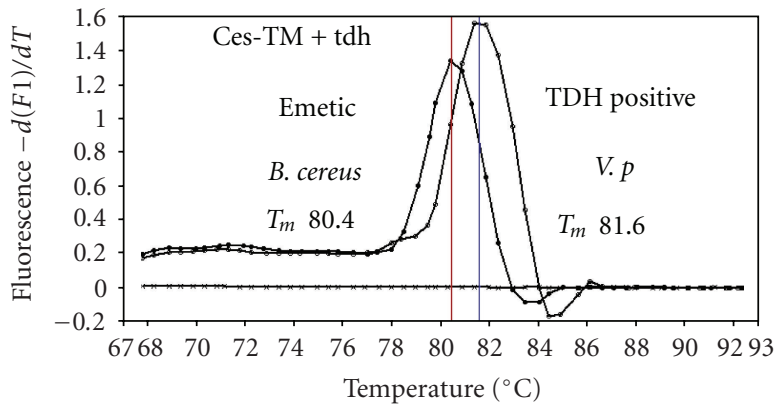

(c)

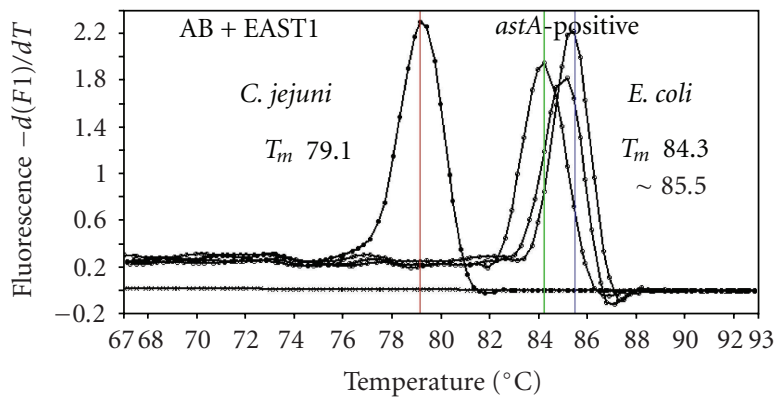

(b)

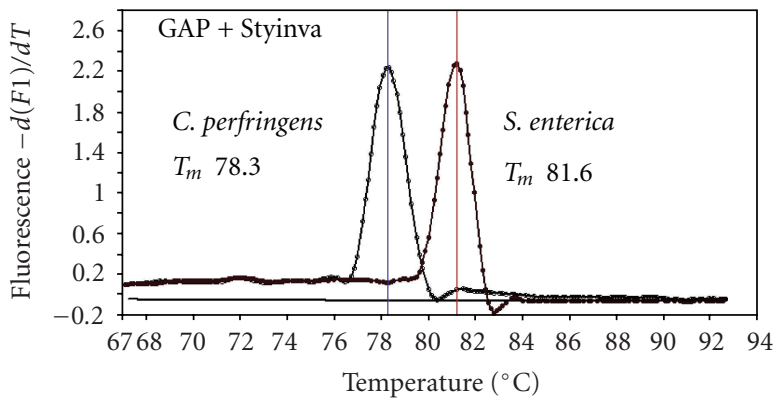

(d)

FIGURe 1: Melting curve analysis of duplex SYBR Green I PCR products in the first run using four primer sets: FemB plus eaeA, AB plus EAST1, ces plus tdh, and GAP plus Styinva.

Duplex SG-PCR rapidly and accurately demonstrated that $12(57.1 \%)$ of 21 cases were caused with a single foodborne pathogen such as $C$. jejuni ( 6 cases), C. perfringens (3 cases), B. cereus (2 cases), and TDH-producing $V$. parahaemolyticus (one case). There were also 7 (33.3\%) cases with plural foodborne bacterial pathogens (such as astApositive E. coli, EPEC, C. jejuni, C. perfringens, A. hydrophila, and $P$. shigelloides) and 2 (9.5\%) cases with foodborne bacterial pathogens (astA-positive E. coli or EHEC O:26) and norovirus. In cases 2 and 10, although detection of norovirus is out of the scope of our work, norovirus and foodborne bacterial pathogens were concomitantly detected by conventional PCR analysis in our virological laboratory. In case 2 in which norovirus was detected in 6 of 7 feces, the ast $A$ gene of EAEC was detected from 7 of 10 feces and then astA-positive $E$. coli strains were isolated from 6 samples. In case 10 in which norovirus was detected from 20 of 22 feces, the eae gene of EPEC or EHEC was detected from 8 of 22 feces and EHEC O26 strains were isolated from 8 of 22 feces. In 7 cases (cases 1, 11, 12, 13, 16, 20, and 21), the pathogenic $E$. coli strains belonging to astA-positive $E$. coli and/or EPEC were concomitantly detected with other foodborne bacterial pathogens. In case 1 , the eae gene of EPEC or EHEC was detected from 4 of 22 feces and the astA gene of EAEC was detected in 3 other feces. However, duplex SG-PCR could not detect other virulent genes, including the $s t \times 1$ and $s t \times 2$ genes of EHEC. Then EPEC strains were later isolated from 5 feces and astA-positive E. coli from 4 other feces. In case 12, the ast A gene of EAEC was detected in all 5 feces and the eae gene of EPEC or EHEC in 2 feces, but duplex SG-PCR could not detect other E. coli virulent genes. The subsequent bacteriological examination could not isolate pathogenic E. coli among nonpathogenic E. coli flora. In case 16, the C. jejuni specific gene was detected in 6 of 9 feces and the astA gene of EAEC was detected in 5 feces (both genes from 3 feces). C. jejuni strains were then isolated from 9 of 14 feces, but we were not able to isolate the pathogenic E. coli strain among nonpathogenic E. coli flora. In cases 19 to 21 analyzed improved real-time PCR using 8 primers for the detection of 7 main foodborne bacteria and astA-positive E. coli, C. jejuni, EPEC, or astA-positive E. coliwere detected from 1 to 3 fecal samples on the first run and the absence of the other main foodborne bacteria in the analyzed samples was readily confirmed. In case 20 , the eae gene of EPEC or EHEC was detected from 2 of 5 fecal samples on the first run and the $\operatorname{gyr} B$ gene of $P$. shigelloideswas detected separately from other 2 fecal samples on the second run. Then $P$. shigelloides strains were isolated from 2 feces, but isolation of the EPEC strain was very difficult due to the presence of large nonpathogenic E. coli flora in the feces.

In almost all cases, the duplex SG-PCR assay first run detected these causative agents from more than one of the five feces. Then, in almost all cases, the presence of a causative agent (presumed from duplex SG-PCR assay) was confirmed by the results of the final SG-PCR assay run and the bacteriological cultivation of additional feces. These findings confirmed that for foodborne outbreaks duplex SGPCR is a useful tool for the rapid detection of both single and multiple pathogens. 


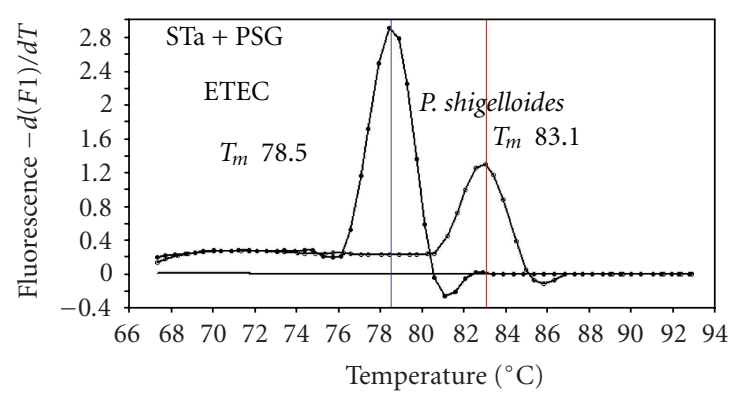

(a)

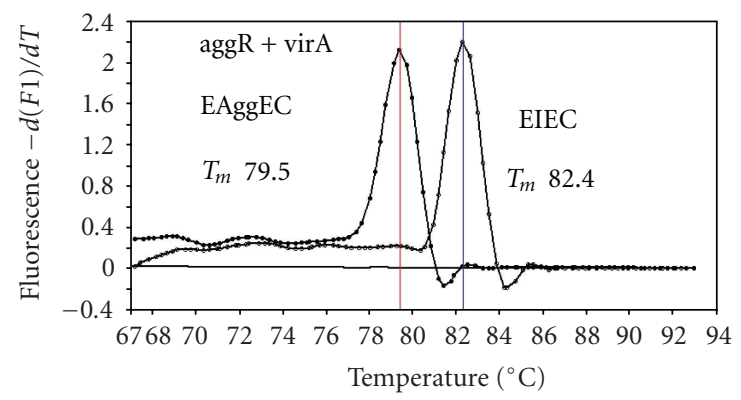

(c)

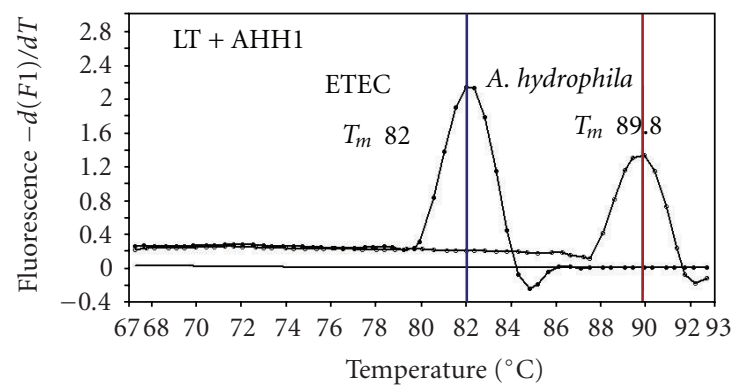

(e)

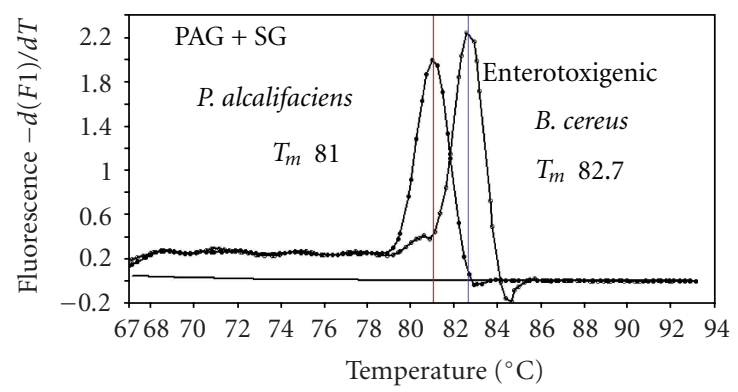

(g)

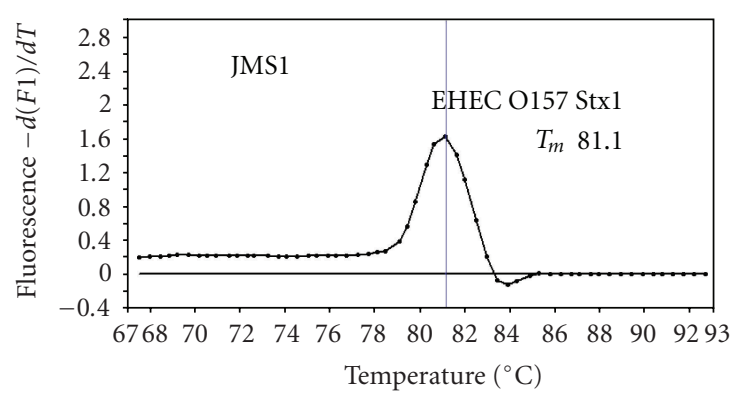

(b)

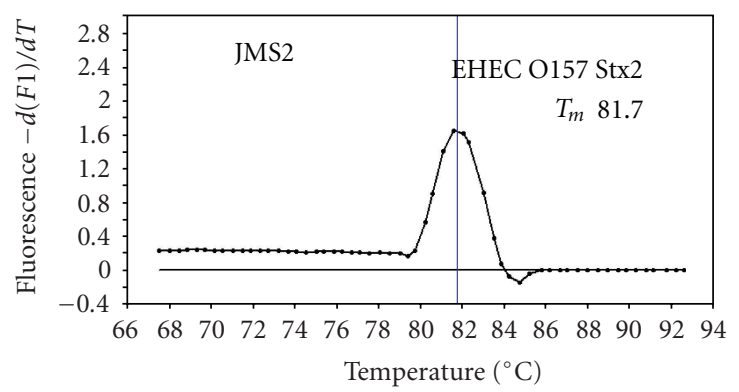

(d)

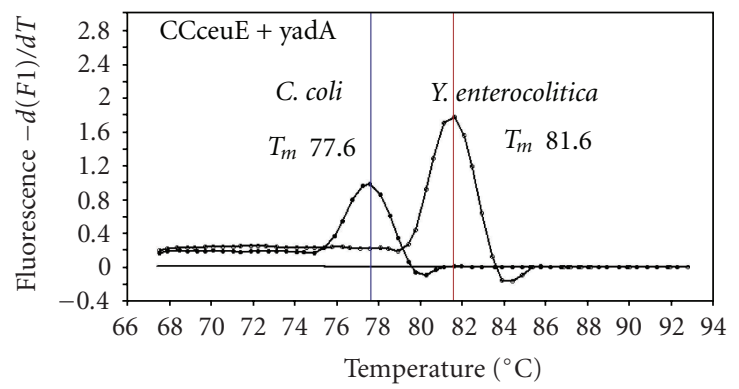

(f)

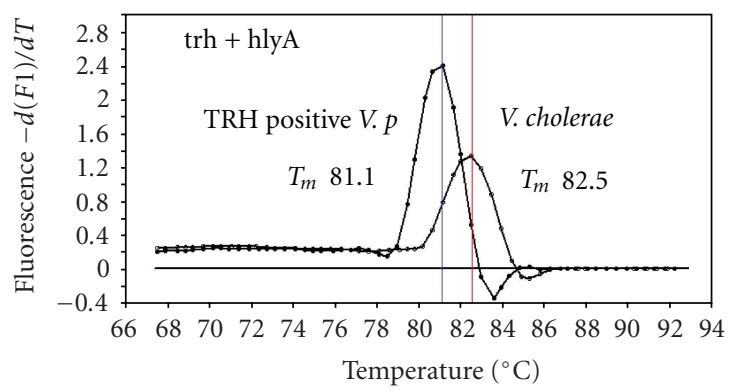

(h)

FIGURE 2: Melting curve analysis of duplex SYBR Green I PCR products in the second run using four primer sets: ST plus PSG, aggR plus virA, LT plus AHH1, and PAG plus SG; the third run using two primer sets: CCcesE plus yadA and trh plus hlyA; simple PCR with primers JMS 1 and JMS2.

3.3. Quantification of the Causative Agent in 14 Foodborne Outbreak Cases. Figure 2 shows the relationship between CFU and DNA copy of foodborne pathogens using SGquantitative PCR (qPCR) assay in 71 feces from 14 cases examined by viable cell counting. There was no correlation $\left(r^{2}=0.1183\right)$ between CFU and DNA copy of foodborne pathogens in feces, although almost all pathogens were detected by SG-PCR from feces registering more than
$10^{3} \mathrm{CFU} / \mathrm{g}$ by viable cell counting. By using SG- qPCR assay combined with DNA extraction using the QIAamp DNA Stool Mini kit, Bibbal et al. [28] reported a significant correlation between CFU and DNA copy of ampicillinresistant Enterobacteriaceae in swine feces. Fu et al. [29] reported a significant correlation between CFU and DNA copy of Lactobacillus and total anaerobic bacteria in dog feces but found no correlation between CFU and DNA copy of 


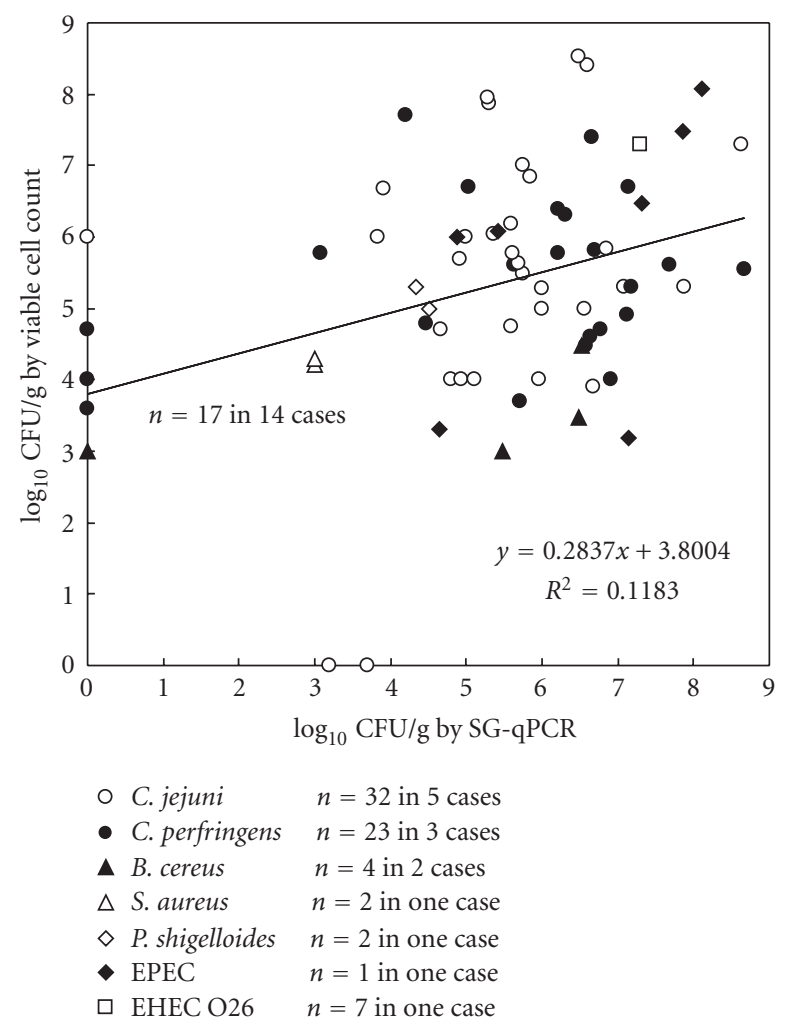

FIgURE 3: The relationship between CFU and DNA copy of foodborne pathogens in 71 foodborne pathogens-positive feces in 14 foodborne outbreak cases examined by viable cell counting.

C. perfringens. Although accurate quantifications of foodborne pathogens, including $C$. jejuni and C. perfringens, in feces were not completely performed by SG-qPCR in this study, the presence of any foodborne pathogens at more than $10^{3} \mathrm{CFU} / \mathrm{g}$ feces was certainly confirmed by melting curve analysis. There are two major problems for these differences. One cause is different sample preparation that was used for $\mathrm{CFU}$ from the feces stored in the transport medium and for qPCR using the mass sample collected for virological inspection. Another cause is the approach used to construct the standard curves that were prepared from pure bacterial cultures. These curves do not relate with the "real" situation of a bacterial quantification in a faecal sample and can in part explain the absence of correlation between CFU and DNA copy of foodborne pathogens in faeces.

In our routine bacteriological diagnostic laboratory, we used duplex SYBR Green I PCR assay combined with DNA extraction via QIAamp DNA Stool Mini kit for the detection of foodborne bacteria from 21 foodborne outbreak cases. The causative bacteria were detected in almost all cases in 2 hours or less. The first run was for the detection of 8 main foodborne bacteria and the second run was for the detection of other unusual suspect bacteria. The results proved that for comprehensive and rapid molecular diagnosis in foodborne outbreaks, duplex SG-PCR assay is not only very useful, but is also economically viable for one-step differentiation of causative bacteria in fecal specimens obtained from symptomatic patients. This then allows for effective diagnosis and management of foodborne outbreak.

\section{Acknowledgment}

This work was supported in part by a grant-in-aid of the Japanese Ministry of Health, Labor and Welfare (H19-Kenki011).

\section{References}

[1] L. Fenicia, F. Anniballi, D. De Medici, E. Delibato, and P. Aureli, "SYBR green real-time PCR method to detect Clostridium botulinum type A," Applied and Environmental Microbiology, vol. 73, no. 9, pp. 2891-2896, 2007.

[2] I. Abubakar, L. Irvine, C. F. Aldus, et al., "A systematic review of the clinical, public health and cost-effectiveness of rapid diagnostic tests for the detection and identification of bacterial intestinal pathogens in faeces and food," Health Technology Assessment, vol. 11, no. 36, pp. 1-216, 2007.

[3] I. M. Mackay, "Real-time PCR in the microbiology laboratory," Clinical Microbiology and Infection, vol. 10, no. 3, pp. 190-212, 2004.

[4] M. Fricker, U. Messelhäußer, U. Busch, S. Scherer, and M. Ehling-Schulz, "Diagnostic real-time PCR assays for the detection of emetic Bacillus cereus strains in foods and recent foodborne outbreaks," Applied and Environmental Microbiology, vol. 73, no. 6, pp. 1892-1898, 2007.

[5] J. Hoorfar, P. Ahrens, and P. Radstrom, “Automated 5' nuclease PCR assay for identification of Salmonella enterica," Journal of Clinical Microbiology, vol. 38, no. 9, pp. 3429-3435, 2000.

[6] Y. Iijima, N. T. Asako, M. Aihara, and K. Hayashi, "Improvement in the detection rate of diarrhoeagenic bacteria in human stool specimens by a rapid real-time PCR assay," Journal of Medical Microbiology, vol. 53, no. 7, pp. 617-622, 2004.

[7] H. J. M. Aarts, R. G. Joosten, M. H. C. Henkens, H. Stegeman, and A. H. A. M. van Hoek, "Rapid duplex PCR assay for the detection of pathogenic Yersinia enterocolitica strains," Journal of Microbiological Methods, vol. 47, no. 2, pp. 209-217, 2001.

[8] H. K. Nogva, A. Bergh, A. Holck, and K. Rudi, "Application of the $5^{\prime}$-Nuclease PCR assay in evaluation and development of methods for quantitative detection of Campylobacter jejuni," Applied and Environmental Microbiology, vol. 66, no. 9, pp. 4029-4036, 2000.

[9] D. De Medici, L. Croci, E. Delibato, S. Di Pasquale, E. Filetici, and L. Toti, "Evaluation of DNA extraction methods for use in combination with SYBR green I real-time PCR to detect Salmonella enterica serotype Enteritidis in poultry," Applied and Environmental Microbiology, vol. 69, no. 6, pp. 3456-3461, 2003.

[10] H. Fukushima, Y. Tsunomori, and R. Seki, "Duplex realtime SYBR green PCR assays for detection of 17 species of food- or waterborne pathogens in stools," Journal of Clinical Microbiology, vol. 41, no. 11, pp. 5134-5146, 2003.

[11] H. Fukushima, K. Katsube, Y. Hata, R. Kishi, and S. Fujiwara, "Rapid separation and concentration of food-borne pathogens in food samples prior to quantification by viablecell counting and real-time PCR," Applied and Environmental Microbiology, vol. 73, no. 1, pp. 92-100, 2007. 
[12] N. Jothikumar and M. W. Griffiths, "Rapid detection of Escherichia coli O157:H7 with multiplex real-time PCR assays," Applied and Environmental Microbiology, vol. 68, no. 6, pp. 3169-3171, 2002.

[13] H. Fukushima and Y. Tsunomori, "Study of real-time PCR assays for rapid detection of food-borne pathogens," Kansenshogaku Zasshi, vol. 79, no. 9, pp. 644-655, 2005.

[14] E. M. Nielsen and M. T. Andersen, "Detection and characterization of verocytotoxin-producing Escherichia coli by automated 5' nuclease PCR assay," Journal of Clinical Microbiology, vol. 41, no. 7, pp. 2884-2893, 2003.

[15] M. Klotz, S. Opper, K. Heeg, and S. Zimmermann, "Detection of Staphylococcus aureus enterotoxins A to D by real-time fluorescence PCR assay," Journal of Clinical Microbiology, vol. 41, no. 10, pp. 4683-4687, 2003.

[16] J. Yatsuyanagi, S. Saito, H. Sato, Y. Miyajima, K.-I. Amano, and K. Enomoto, "Characterization of enteropathogenic and enteroaggregative Escherichia coli isolated from diarrheal outbreaks," Journal of Clinical Microbiology, vol. 40, no. 1, pp. 294-297, 2002.

[17] M. Nishibuchi, Y. Takeda, J. Tada, et al., "Methods to detect the thermostable direct hemolysin gene and a related hemolysin gene of Vibrio parahaemolyticus by PCR," Nippon Rinsho, vol. 50, supplement, pp. 348-352, 1992 (Japanese).

[18] N. Kato, S. M. Kim, H. Kato, et al., "Identification of enterotoxin-producing Clostridium perfringens by the polymerase chain reaction," The Journal of the Japanese Association for Infectious Diseases, vol. 67, no. 8, pp. 724-729, 1993.

[19] S. M. Franck, B. T. Bosworth, and H. W. Moon, "Multiplex PCR for enterotoxigenic, attaching and effacing, and Shiga toxin-producing Escherichia coli strains from calves," Journal of Clinical Microbiology, vol. 36, no. 6, pp. 1795-1797, 1998.

[20] E. Villalobo and A. Torres, "PCR for detection of Shigella spp. in mayonnaise," Applied and Environmental Microbiology, vol. 64, no. 4, pp. 1242-1245, 1998.

[21] G. Wang, C. G. Clark, C. Liu, et al., "Detection and characterization of the hemolysin genes in Aeromonas hydrophila and Aeromonas sobria by multiplex PCR," Journal of Clinical Microbiology, vol. 41, no. 3, pp. 1048-1054, 2003.

[22] F. Itoh, T. Ogino, K. Itoh, and H. Watanabe, "Differentiation and detection of pathogenic determinants among diarrheogenic Escherichia coli by polymerase chain reaction using mixed primers," Nippon Rinsho, vol. 50, supplement, pp. 343-347, 1992 (Japanese).

[23] I.-C. Yang, D. Y.-C. Shih, J.-Y. Wang, and T.-M. Pan, "Development of rapid real-time PCR and most-probable-number real-time PCR assays to quantify enterotoxigenic strains of the species in the Bacillus cereus group," Journal of Food Protection, vol. 70, no. 12, pp. 2774-2781, 2007.

[24] M. Skurnik and H. Wolf-Watz, "Analysis of the yopA gene encoding the Yop1 virulence determinants of Yersinia spp.", Molecular Microbiology, vol. 3, no. 4, pp. 517-529, 1989.

[25] I. Gonzalez, K. A. Grant, P. T. Richardson, S. F. Park, and M. D. Collins, "Specific identification of the enteropathogens Campylobacter jejuni and Campylobacter coli by using a PCR test based on the ceuE gene encoding a putative virulence determinant," Journal of Clinical Microbiology, vol. 35, no. 3, pp. 759-763, 1997.

[26] J. P. Nataro, D. Yikang, D. Yingkang, and K. Walker, "AggR, a transcriptional activator of aggregative adherence fimbria I expression in enteroaggregative Escherichia coli;" Journal of Bacteriology, vol. 176, no. 15, pp. 4691-4699, 1994.
[27] Y. Nishikawa, J. Ogasawara, A. Helander, and K. Haruki, "An outbreak of gastroenteritis in Japan due to Escherichia coli O166," Emerging Infectious Diseases, vol. 5, no. 2, p. 300, 1999.

[28] D. Bibbal, V. Dupouy, J. P. Ferré, et al., "Impact of three ampicillin dosage regimens on selection of ampicillin resistance in Enterobacteriaceae and excretion of bla $a_{\text {TEM }}$ genes in swine feces," Applied and Environmental Microbiology, vol. 73, no. 15, pp. 4785-4790, 2007.

[29] C. J. Fu, J. N. Carter, Y. Li, J. H. Porter, and M. S. Kerley, "Comparison of agar plate and real-time PCR on enumeration of Lactobacillus, Clostridium perfringens and total anaerobic bacteria in dog faeces," Letters in Applied Microbiology, vol. 42, no. 5, pp. 490-494, 2006. 

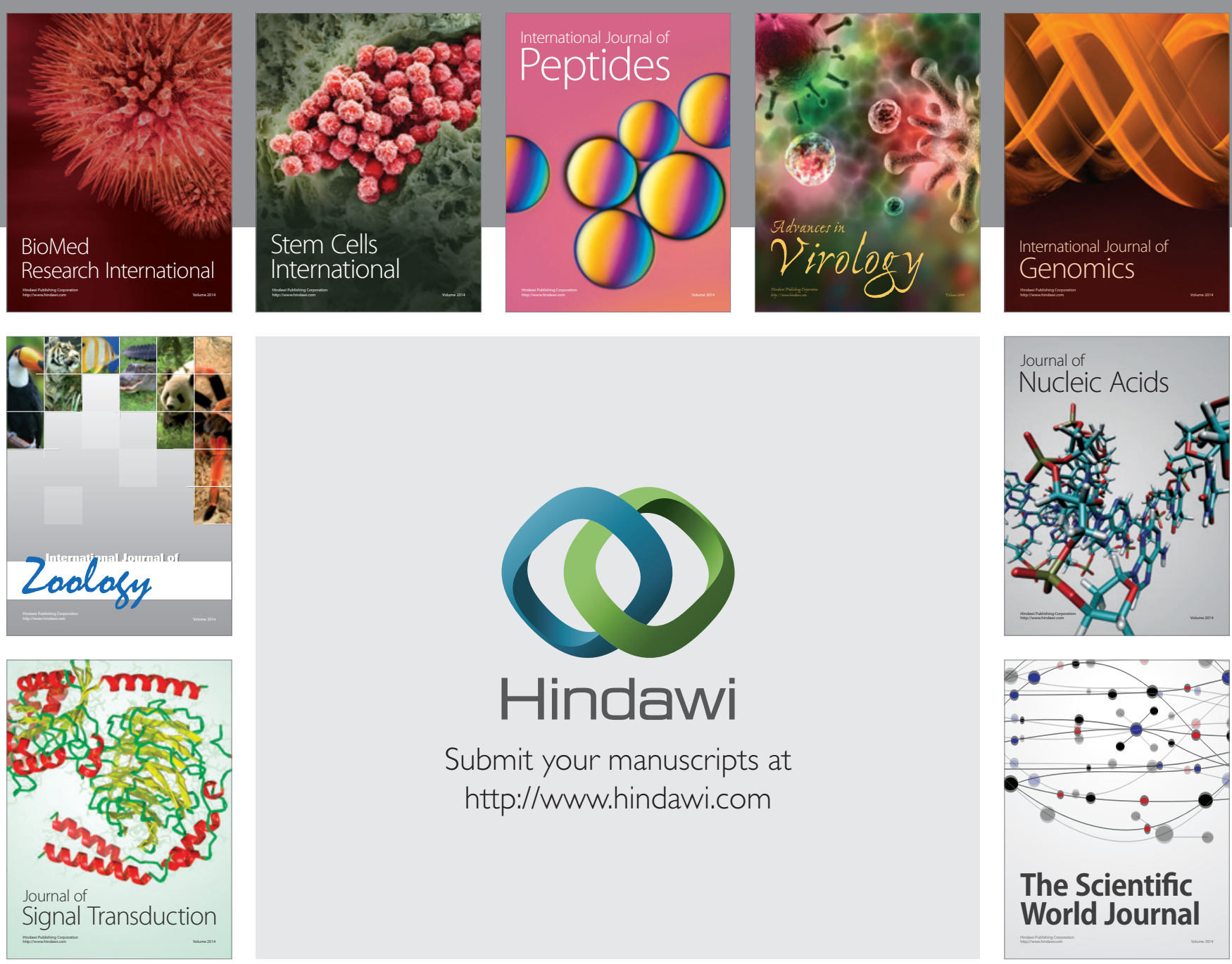

Submit your manuscripts at

http://www.hindawi.com
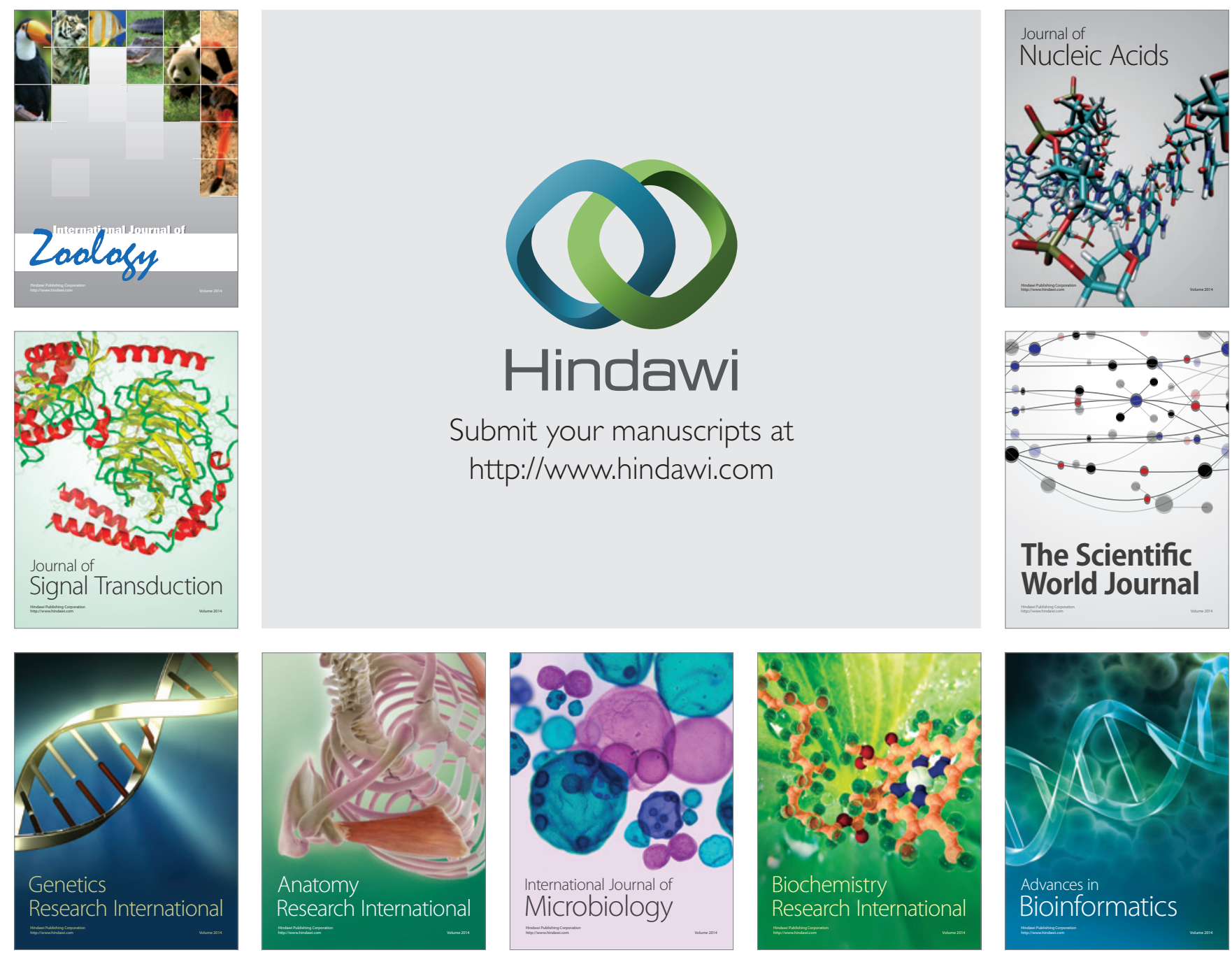

The Scientific World Journal
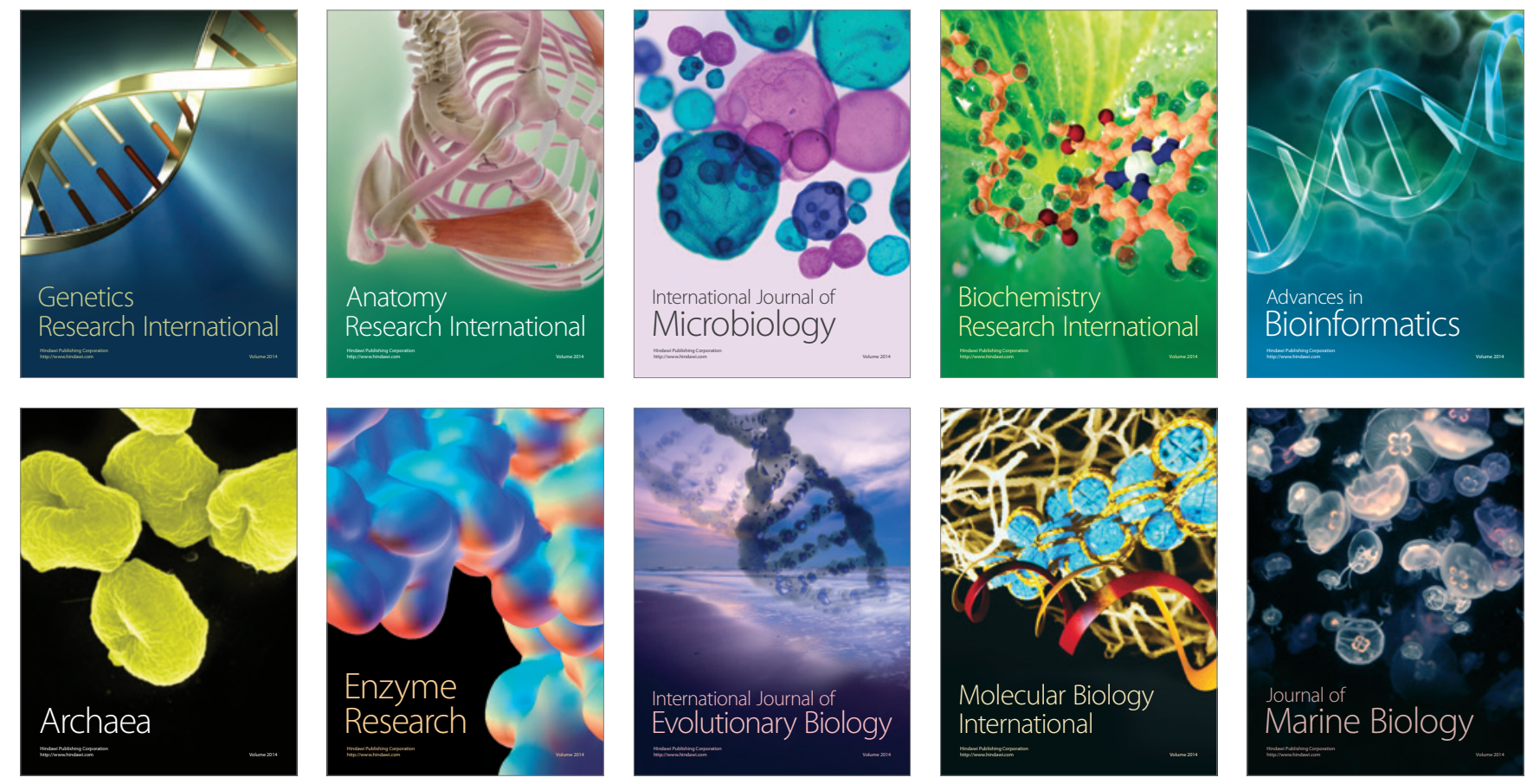